Discussion Papers

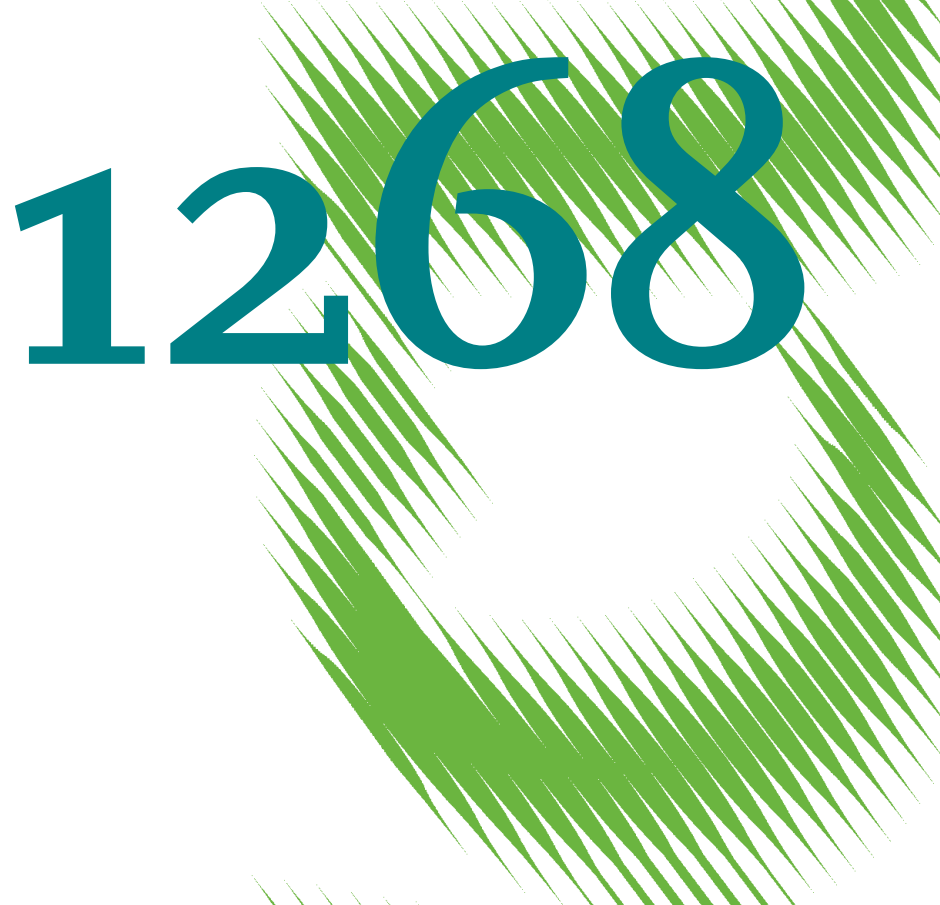

Market Driven Power Plant Investment Perspectives in Europe Climate Policy and Technology Scenarios until 2050 in the Model EMELIE-ESY 
Opinions expressed in this paper are those of the author(s) and do not necessarily reflect views of the institute.

IMPRESSUM

(C) DIW Berlin, 2013

DIW Berlin

German Institute for Economic Research

Mohrenstr. 58

10117 Berlin

Tel. $+49(30) 89789-0$

Fax +49 (30) $89789-200$

http://www.diw.de

ISSN print edition $1433-0210$

ISSN electronic edition 1619-4535

Papers can be downloaded free of charge from the DIW Berlin website:

http://www.diw.de/discussionpapers

Discussion Papers of DIW Berlin are indexed in RePEc and SSRN:

http://ideas.repec.org/s/diw/diwwpp.html

http://www.ssrn.com/link/DIW-Berlin-German-Inst-Econ-Res.html 


\title{
Market Driven Power Plant Investment Perspectives in Europe: \\ Climate Policy and Technology Scenarios until 2050 in the Model EMELIE-ESY ${ }^{1}$
}

\author{
Andreas Schröder \\ Thure Traber ${ }^{2}$ \\ Claudia Kemfert
}

\begin{abstract}
EMELIE-ESY is a partial equilibrium model with focus on electricity markets. Private investors optimize their generation capacity investment and dispatch over the horizon 2010 to 2050 . In the framework of the Energy Modeling Forum 28, we investigate how climate policy regimes affect market developments under different technology availabilities and climate policies on the European power markets. The model projects an only minor increase of power consumption because of higher wholesale prices or energy efficiency current climate policy, and a balanced consumption pathway under ambitious climate policy. These results contrast with findings of POLES and PRIMES models in the reference case that predict unexpected heavy consumption increases by 2050 . By contrast, we find no investment into Carbon Capture and Storage (CCS) and a diminishing share of nuclear energy. We find that renewable energy supply extension as projected can sufficiently meet electricity consumption complemented by only few capacity investments in conventional technology.
\end{abstract}

Keywords Electricity markets, investment, climate policy

1 Financial support by the Mercator foundation is gratefully acknowledged.

2 Corresponding author: German Institute for Economic Research (DIW Berlin), Mohrenstr. 58, D-10117 Berlin, Germany; Email: ttraber@diw.de, Tel.: +49-30-89789409, Fax: +49-30-89789113. 


\section{Introduction}

With EMELIE-ESY we supplement the EMF28 model comparison with a partial equilibrium model to gain detailed sector-specific perspectives. EMF 28 defines different climate policy regimes as well as specifically available power technologies. In our model, investments in power capacities are driven by the prices received on the electricity market as opposed to its value for the system.. In the EMF framework, we expect real fossil fuel prices to grow significantly over the next decades. Under ambitious climate policy the price of emissions in the European emission trading system is also expected to increase. Both prices therefore determine an upward trend for cost of conventional electricity generation which triggers price increases on the electricity markets. Although price elasticity of electricity is comparatively small in the short run, in the long term perspective investigated within EMF 28 consumption is likely to react on prices.

The perspective of the EMELIE-ESY model adds a specific insight into the functioning of electricity markets. The inclusion of hourly power dispatch allows for a detailed depiction of realistic power plant usage, price profiles and technology investment choices. In the model application presented here, we go beyond merely comparing values to other models. Instead, we investigate fundamental determinants of model results. This helps us assessing the implications of climate policy targets on technology choices for conventional power plants. We study the impact of climate policies and technology availability on market outcomes with regard to investment choices and the power mix. We find that the European electricity sector will be able to meet stringent climate policy targets without relying on contentious technologies such as nuclear power and CCS if an accelerated role out of renewable energy is realized. EMELIE-ESY demonstrates how the conventional sector develops under these targets relying on forces induced by power and emissions markets. After the introduction, key model features are outlined and the different scenarios are explained. The results are presented, followed by a conclusion.

\section{Model}

EMELIE-ESY is a partial equilibrium model of the power sector. Aiming for profit maximization, agents make investment decisions and dispatch decisions. EMELIE-ESY combines the dispatch model ESYMMETRY (Traber \& Kemfert 2011a) and the investment model EMELIE (Traber \& Kemfert 2011b). It hence constitutes an integrated multi-period investment-dispatch model, coded as Mixed Complementarity Problem (MCP) in GAMS software. The algebra of the model formulation is presented in Traber and Kemfert (2012), where price taking behavior for all producers and investors is assumed in the application used for EMF 28.

\subsection{Regional resolution}

In terms of regional resolution, the model application includes all countries of the EU-27 plus Norway and Switzerland. While the main central European markets are represented by country, some more peripheral regions are grouped together. Figure 1 provides an overview of the regional disaggregation. Spain and Portugal are grouped into IBERIA; Great Britain and Ireland are included as BRITISH ISLES; Denmark, Sweden, and Finland constitute the regional aggregate NORDIC; Lithuania, Latvia, and Estonia are represented as BALTIC, while the group SOUTHEAST comprises Slovakia, Slovenia, Hungary, Romania, Bulgaria, and Greece. Finally, Belgium and Luxemburg are merged in one group. 


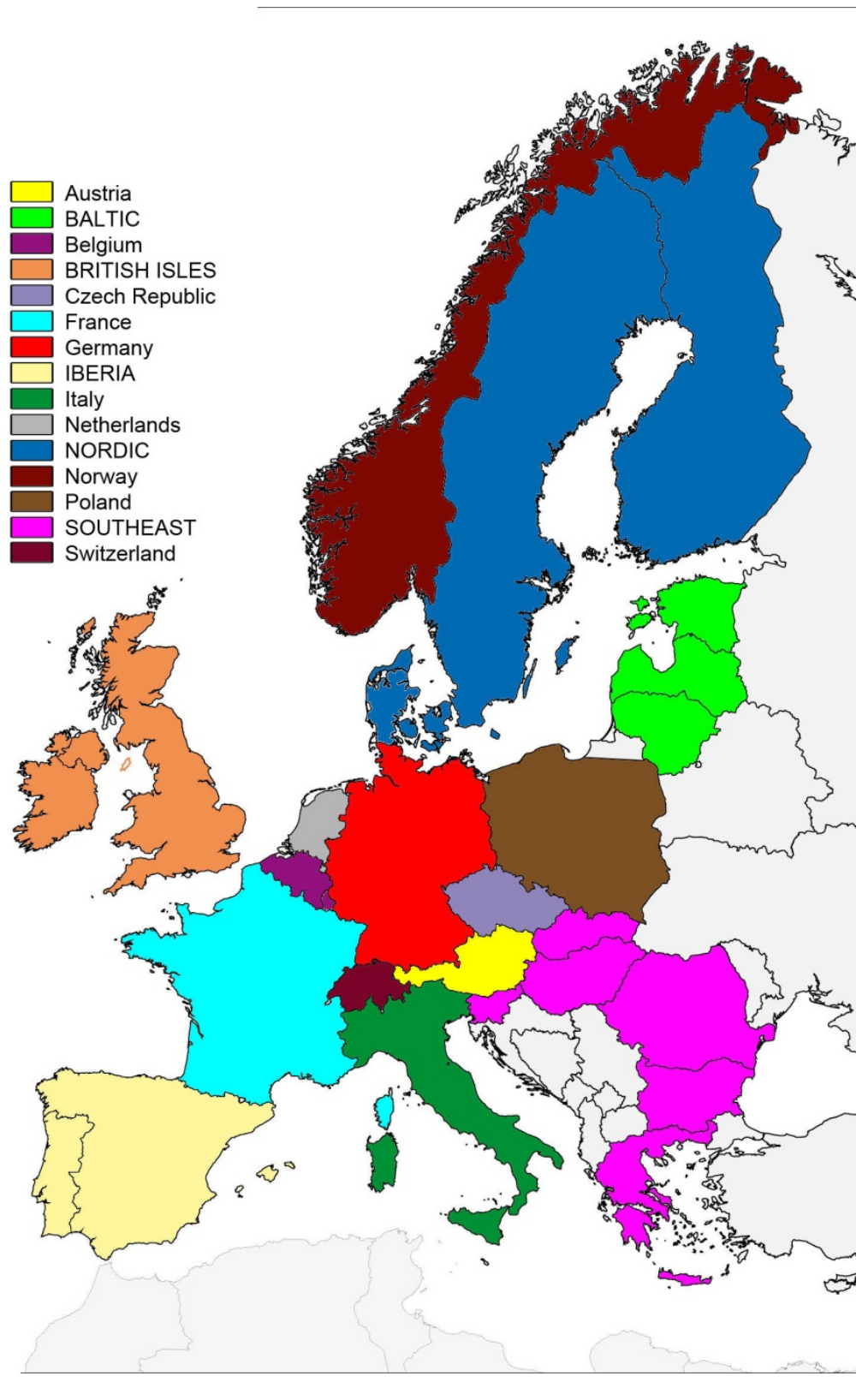

Figure 1: Regional resolution of EMELIE-ESY

(Source: Own illustration)

\subsection{Temporal resolution}

The temporal coverage ranges from 2010 to 2050 in 10 year periods. Each period is represented by 24 consecutive hours, i.e. one day in hourly resolution. On the demand side, average hourly demand values of the year 2010 published by ENTSOE are used. On the supply side, conventional generation including hydro power is modeled endogenously, taking into account ramping restrictions at the dispatch stage to represent the inflexibilities in the generation. By contrast, the hourly supply profile of wind, biomass and solar power generation is fixed and is explained further in subsection "energy efficiency and renewable energy" below. The temporal periodic representation aims at a representation which is relevant for the investor, but does not take into account less probable extreme events, where, for instance, the production of wind power is extremely low. 


\subsection{Transmission}

The projections of the grid structure and corresponding net transfer capacities (NTCs) between countries are taken from ENTSO-E (2012). Winter and Summer NTCs are taken to build averages. The expansion of the grid is in line with the EC Roadmap (EC 2011). The EMELIE-ESY model represents import-export-transfers between countries in a piping model with scarcity pricing as outlined in Traber and Kemfert (2012).

\section{Scenarios}

The scenarios were developed within EMF 28. They are grouped along a technology availability dimension (horizontal) and a policy dimension (vertical). Table 1 provides an overview of the scenarios. Technology scenarios that assume reference values are indicated "ref", while "off" denotes the non-availability of CCS technology, "low" indicates a more restricted potential for nuclear power plants, "high" stands for a less pronounced growth in electricity demand and "opt” assumes a more optimistic development of renewable energies. The corresponding assumptions of the technology availability dimension in our model are explained in more detail in the following subsections. The emission policy dimension essentially prescribes a reduction of greenhouse gas emissions until 2050 by $40 \%$ in the reference case and by $80 \%$ in the mitigation scenario, respectively compared to values of 1990. These policies are implemented in EMELIE-ESY by emission caps for the electricity sector, which in line with the Energy Roadmap has to reduce emissions even faster than the aforementioned economy wide target. In line with the energy roadmap, we use targets which gradually reduce the carbon emission of the electricity sector by two thirds in the reference case and by 97.2 percent in the mitigation scenario compared to sectoral carbon emissions in 2010 (1.265 GT CO2).

\begin{tabular}{|l|c|c|c|c|c|}
\hline & $\begin{array}{c}\text { Default w } \\
\text { CCS }\end{array}$ & $\begin{array}{c}\text { Default w/o } \\
\text { CCS }\end{array}$ & Pessimistic & Optimistic & Green \\
\hline CCS & on & off & off & on & off \\
\hline Nuclear energy & ref & ref & low & ref & low \\
\hline Energy efficiency & ref & ref & ref & high & high \\
\hline Renewable energies & ref & ref & ref & ref & opt \\
\hline $\begin{array}{l}\text { Reference: including the } \\
2020 \text { targets and 40\% } \\
\text { GHG reduction by 2050 }\end{array}$ & EU1 & EU2 & EU3 & EU4 & EU5 \\
\hline $\begin{array}{l}\text { Mitigation: 80\% GHG } \\
\text { reduction by 2050 (with } \\
\text { Cap\&Trade within the EU) }\end{array}$ & EU6 & EU7 & EU8 & EU9 & EU10 \\
\hline
\end{tabular}

\section{Table 1: Scenario overview}

(Source: Own illustration)

\subsection{Energy efficiency and renewable energy}

Electricity consumption is endogenous and represented as linear, country specific demand functions in the model defined by reference points of consumption and prices for each region together with the assumed demand elasticity at reference point. Price-elasticity of demand in the reference point is set to 0.3 throughout all time periods and regions. Starting from reference values in regard to prices and consumption of the year $2010^{3}$, reference

\footnotetext{
3 Reference prices are taken from several European energy exchanges. We use for the specification of the Norwegian, Nordic and Baltic markets Nordpool prices, for Poland and Czech Republic Polish Power Exchange prices(exchange rate 4.2 Zloty per Euro), for Switzerland SWISSIX prices (EEX), and for the remaining regions
} 
consumption is set to increase by $10 \%$ per decade for OECD countries and $20 \%$ per decade for non-OECD countries. In the energy efficiency "high" scenario, reference demand only grows by 5 and 10\% per decade respectively. Notably, these parameter values leave room for actual reductions in the consumption of electricity given price increases as laid out in the results section.

Renewable energy capacities, i.e. wind, solar radiation, biomass, and hydro are treated as exogenous based on the National Renewable Energy Action Plans ${ }^{4}$ (NREAPs) up to 2020, and a trend projection until 2050. We assume a linear trend expansion of the renewable energy capacities up to 2050 in the renewable energy reference ("Ref") case. For the renewable energy scenario "opt", renewable energy capacities based on wind, solar radiation and biomass is increased against the reference scenario of 10, 20, and 30 percent by the years 2030, 2040 and 2050 respectively. Their hourly supply profile is fixed in each scenario and based on the average German profiles, scaled to the generation values of the National Renewable Energy Action Plans (NREAPs) to represent different regions.

\subsection{Conventional generation technologies}

14 generation technologies are included in the analysis as indicated in Table 2. Coal-fired plants are sub-divided by vintage and fuel type. Gas- and oil-fired plants are divided by turbine type. Nuclear power plants are only distinguished by vintage, in order to reflect evolutions from ordinary generation III reactors towards new-type reactors such as EPR and AP-1000.

\begin{tabular}{|l|l|l|}
\hline Group & Description & IIASA Denomination \\
\hline \multirow{4}{*}{ Nuclear } & Generation 3 Old Nuclear & Nuclear \\
\cline { 2 - 3 } & Generation 3 Nuclear & Nuclear \\
\hline \multirow{5}{*}{ Coal } & Lignite Subcritical & Coal|PC|w/o CCS \\
\cline { 2 - 3 } & Lignite Supercritical & Coal|PC|w/o CCS \\
\cline { 2 - 3 } & Old Subcritical & Coal|PC|w/o CCS \\
\cline { 2 - 3 } & Coal Supercritical & Coal|PC|w/o CCS \\
\cline { 2 - 3 } & Lignite Oxyfuel CCS & Coal|PC|w CCS \\
\cline { 2 - 3 } & Coal IGCC CCS & Coal|IGCC|w CCS \\
\hline \multirow{5}{*}{ Gas } & Gas Precomb. CCS & Gas|CC|w CCS \\
\cline { 2 - 3 } & Gas Combined Cycle & Gas|CC|w/o CCS \\
\cline { 2 - 3 } & Gas Combustion Turbine & Gas|CT \\
\cline { 2 - 3 } & Gas Steam Turbine & Gas|CT \\
\hline \multirow{2}{*}{ Oil } & Oil Steam Turbine & Oil|w/o CCS \\
\cline { 2 - 3 } & Oil Combustion Turbine & Oil|w/o CCS \\
\hline Hydro & Hydroelectric & Hydro \\
\hline
\end{tabular}

Table 2: Conventional Technologies

(Source: Own illustration)

The technologies available for investment in the EMELIE-ESY framework are described in Table 3 below. The costs and possible revenues are characterized by significant range of investment costs between 6000 Euro per $\mathrm{kW}$ (Schroeder et al. forthcoming) for new EPR nuclear reactors to 400 Euro per $\mathrm{kW}$ single cycle gas turbines (Gas GT). Following the 
assumed potential for technological development, investment costs of CCS-Technologies, nuclear reactors and combined cycle gas turbines show a decreasing cost trend, whereas it is assumed for other more developed technologies to have constant investment costs expressed in current money value. 


\begin{tabular}{|l|l|c|c|c|c|c|}
\hline & $\begin{array}{l}\text { Investment cost in } \\
\mathbf{E U R}_{\mathbf{2 0 1 0}} / \mathbf{k W}\end{array}$ & $\mathbf{2 0 1 0}$ & $\mathbf{2 0 2 0}$ & $\mathbf{2 0 3 0}$ & $\mathbf{2 0 4 0}$ & $\mathbf{2 0 5 0}$ \\
\hline NUCLEAR & Generation 3 Nuclear & 6000 & 5833 & 5671 & 5513 & 5360 \\
\hline \multirow{4}{*}{ COAL } & Coal IGCC CCS & 2988 & 2794 & 2613 & 2443 & 2285 \\
\cline { 2 - 7 } & Coal Supercritical & 1300 & 1300 & 1300 & 1300 & 1300 \\
\cline { 2 - 7 } & Lignite Supercritical & 1700 & 1700 & 1700 & 1700 & 1700 \\
\cline { 2 - 7 } & Lignite Oxyfuel CCS & 3881 & 3577 & 3296 & 3038 & 2800 \\
\hline \multirow{3}{*}{ GAS } & Gas Precomb. CCS & 1637 & 1528 & 1425 & 1330 & 1241 \\
\cline { 2 - 7 } & Gas Combined Cycle & 800 & 764 & 729 & 696 & 664 \\
\cline { 2 - 7 } & Gas Combustion Turbine & 400 & 400 & 400 & 400 & 400 \\
\hline
\end{tabular}

Table 3: Investment costs.

Furthermore, investment options are distinct by their characteristics regarding efficiency, operation and maintenance costs, start-up fuel requirements, ramping limits, fuel emissions, start-up depreciation and availability. Here we assume fixed values over the model time horizon as laid out in Table 4. We have to note that we included a waste disposal tag on O\&M costs for nuclear power.

\begin{tabular}{|c|c|c|c|c|c|c|c|}
\hline & Efficiency & $\begin{array}{c}\begin{array}{c}\text { O\&M } \\
\text { costs }\end{array} \\
\text { [cent/kWh] }\end{array}$ & \begin{tabular}{|c}
$\begin{array}{c}\text { Start-up } \\
\text { fuel }\end{array}$ \\
{$[\mathbf{k W h} / \mathbf{k W}]$}
\end{tabular} & $\begin{array}{c}\text { Maximum } \\
\text { load } \\
\text { gradient } \\
\text { [\%/hour] }\end{array}$ & $\begin{array}{c}\begin{array}{c}\text { Fuel } \\
\text { emission }\end{array} \\
{[\mathrm{kg} / \mathbf{k W h}]} \\
\end{array}$ & $\begin{array}{c}\begin{array}{c}\text { Start-up } \\
\text { depreceation }\end{array} \\
\text { [cent/kW] } \\
\end{array}$ & $\begin{array}{c}\text { Avail- } \\
\text { ability } \\
\text { [\%] }\end{array}$ \\
\hline Nuclear & 0,34 & 1,8 & 16,7 & 0,04 & 0,00 & 0,5 & 0,81 \\
\hline $\begin{array}{l}\text { Coal } \\
\text { CCS }\end{array}$ & 0,40 & 3,6 & 8,0 & 0,30 & 0,04 & 0,5 & 0,84 \\
\hline Coal & 0,46 & 0,6 & 6,2 & 0,30 & 0,35 & 0,5 & 0,82 \\
\hline Lignite & 0,43 & 0,6 & 6,2 & 0,08 & 0,40 & 0,3 & 0,85 \\
\hline $\begin{array}{l}\text { Lignite } \\
\text { CCS }\end{array}$ & 0,31 & 4,1 & 8,0 & 0,08 & 0,05 & 0,3 & 0,87 \\
\hline $\begin{array}{l}\text { Gas } \\
\text { CCS }\end{array}$ & 0,48 & 1,9 & 2,0 & 0,30 & 0,02 & 1,0 & 0,92 \\
\hline Gas CC & 0,60 & 0,2 & 2,0 & 0,50 & 0,20 & 1,0 & 0,92 \\
\hline Gas GT & 0,45 & 0,2 & 1,1 & 1,00 & 0,20 & 0,5 & 0,92 \\
\hline
\end{tabular}

Table 4: Technological characteristics

The last driver of the full costs of generation is the central assumption in regard to fuel prices. In order to attain model comparability, we follow fuel price assumption in line with IEA projections (IEA 2011) and closely in line with partner models as laid out below in Table 5. 


\begin{tabular}{|c|c|c|c|c|c|}
\hline Euro $2010_{\text {20 }} \mathbf{M W h}_{\text {fuel }}$ & $\mathbf{2 0 1 0}$ & $\mathbf{2 0 2 0}$ & $\mathbf{2 0 3 0}$ & $\mathbf{2 0 4 0}$ & $\mathbf{2 0 5 0}$ \\
\hline Lignite & 0,3 & 0,4 & 0,4 & 0,5 & 0,5 \\
\hline Hard Coal & 1,3 & 1,3 & 1,4 & 1,6 & 1,7 \\
\hline Natural Gas & 2,3 & 3,0 & 3,4 & 3,7 & 4,1 \\
\hline Uranium & 0,2 & 0,2 & 0,2 & 0,2 & 0,2 \\
\hline
\end{tabular}

\section{Table 5: Fuel price development}

The potential construction of new generation capacities is limited exogenously in line with existing and near-term planning up to 2020 as indicated in the Platts database (Platts 2011). For the period from 2030 onwards, we use a heuristic to approximate investment limits based on the replacement of retiring capacities. More precisely, natural gas and hard coal investments are allowed to overcompensate the decommissioning according to lifetime expectancy by $100 \%$, while investments in lignite capacities may at most replace decommissioning. In the scenarios denoted "ref" nuclear technology construction is confined to currently planned projects until 2020 or to the amount of decommissioned capacity in the corresponding decade if the latter number is greater. For the decades following 2020 current plans until 2020 are used as a proxy for planning. Only in Germany, decommissioning of old capacities does not imply the option of new investments. Notably, this scenario disregards policy decisions taken in countries like Belgium and Sweden and, thus, indicates an optimistic potential for nuclear investments. By contrast, in the scenario nuclear "low" nuclear production relies on existing capacities or plants currently under construction which are decommissioned after 50 years of lifetime or according to the German nuclear phase-out policy. Finally, CCS in scenario "ref" follows the expansion limits of ordinary gas and coal plants as indicated above, while the scenario CCS "off” does not allow for construction of CCS power plants.

\section{Results}

We compare our results explicitly to the model PRIMES and to POLES. PRIMES is used as a reference model since it is frequently used for the the European Commission (EC 2011) for instance the influential EU Energy Roadmap. POLES is used for its similar format as partial equilibrium model with detailed treatment of power markets.

\subsection{Wholesale electricity price projection}

EMELIE-ESY is designed to calculate plausible electricity wholesale prices in the long run. The model therefore relies on long run marginal cost pricing plus an additional price component which reflects ramping costs of power plants. Therefore, electricity prices in our model cover all costs for the operators and investors of the marginal power plant, i.e. the investment which just breaks even with a return of 8 percent per year.

The comparison of the average volume weighted wholesale electricity price projections in Figure 2 essentially reveals three distinct pathways. They range from a pronounced increase of 190 percent until 2050 compared to 2010 in the most pessimistic scenario EU8 to the scenario EU 5, in which prices increase 20 percent by 2050. In EU5, with high energy efficiency and an accelerated renewable energy roll out, the price increase on the wholesale market only compensates for a minor fraction of the variable fuel cost increase of a gas fired power station of about $110 \%$ in the same period. Taking into account a reduction of plant utilization induced by renewable energies, it follows that the profitability of a gas power station significantly reduces in EU5 over time. 


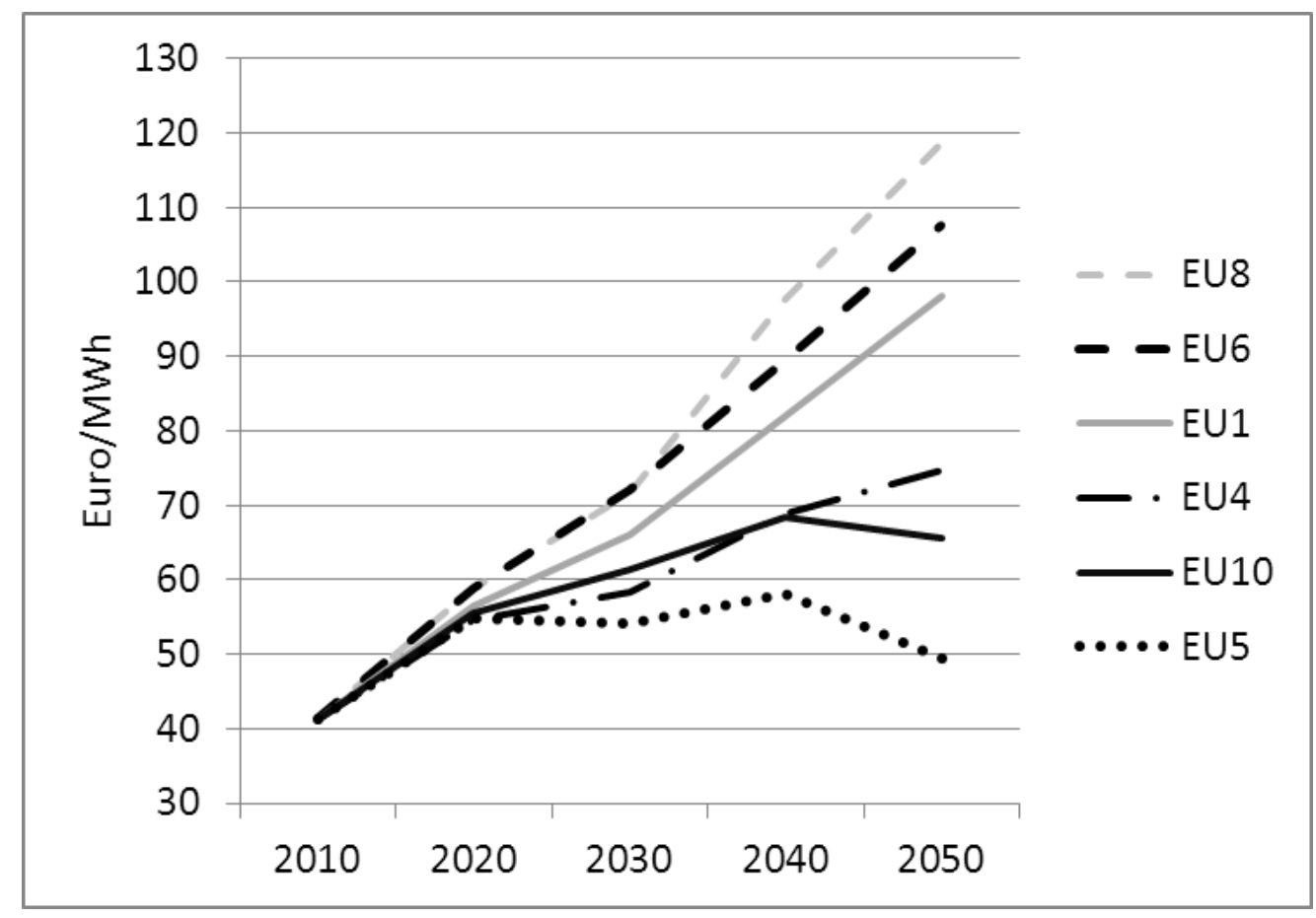

Figure 2: Wholesale Electricity Prices EU-27 average

(Source: Own illustration)

Between the two extreme cases we find an intermediate price pathway taken on in scenarios with high energy efficiency and either a not ambitious climate policy (EU4) or a high renewable energy roll out (EU10), which lead to price increases of 81 and 59 percent respectively. They set apart from the high price scenarios EU8/6/1 already by the year 2020 which either assume a less ambitious climate policy (EU1) or a combination of low increases in energy efficiency with (EU6) or without (EU8) the option of nuclear power plant construction. The difference of the latter scenarios is the wholesale price effect of newly built nuclear power plants, which amounts to 27 percent of the price level in the first period. Finally, the price projection of scenario EU9 (not shown) corresponds closely to the development in EU6. This indicates the potential of increased energy efficiency to compensate price effects induced by more stringent climate policy under our assumptions.

Prices in other EMF 28 models differ in the way they are composed and in their type (wholesale versus end-user prices, average versus maximum). A rough comparison of results shows that electricity prices calculated by EMELIE-ESY are in a variety of scenarios higher as compared to most other models. The prices reported by other models often seem not to cover full cost of investment always. Instead, investment seems to be triggered even at low producer prices due to minimum capacity constraints and implicit additional revenue components. However, pronounced electricity consumption increase as documented for POLES and PRIMES in subsection 4.4. occurs despite significant increases in the fuel and investment costs of marginal power plants, which opens up a question with regard to the demand elasticity used in those models. 


\subsection{Emission market prices}

In regard to emission prices induced by the European emission trading system, our results correlate closely with the wholesale price developments laid out in the previous section. Notably, in the scenario with a more ambitious renewable energy roll out and less ambitious climate policy EU5 we find even a decreasing price path after 2020 as laid out in Figure 3 below.

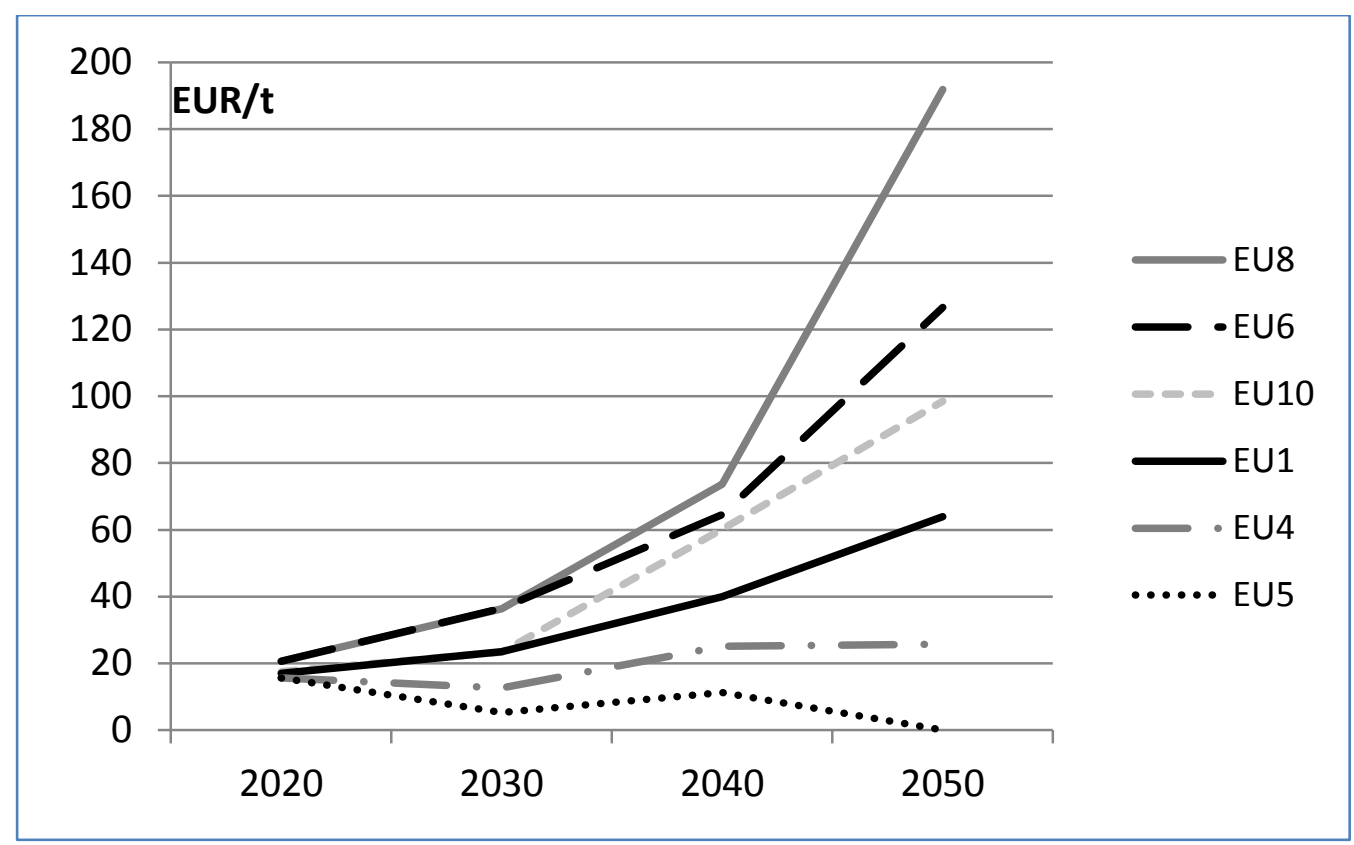

\section{Figure 3: Emission Prices}

The comparison of our findings with POLES and PRIMES shows that the models compute similar emission prices in the reference scenarios in both climate policy cases at least until 2040. Under reference climate policy and reference technology assumptions of scenario EU1, the emission price projection of EMELIE-ESY shows an only slightly more pronounced increase with an emission price of $65 €$ per tonne of $\mathrm{CO}_{2}$ by 2050. To the contrary, the closely related emission price pathways of POLES and PRIMES deviate from our results significantly in the ambitious climate policy scenario EU6. In scenarios EU6, EU8 and EU 10 we find comparatively less accentuated emission prices with maximal values ranging between 98 and 192 Euro in 2050. In the same scenario group POLES reports emission prices of between 240 and 3629 Euro by 2050, while PRIMES respective results are between 270 and 290 Euro per tonne of $\mathrm{CO}_{2}$.

Comparing these ranges highlights the intermediate sensitivity of EMELIE ESY in regard to prices. In particular, the difference in emission prices between scenarios EU6 and EU8 reveals the balanced sensitivity of the model with regard to the availability of nuclear power as an option and leads to an emission price tag of 65 Euro per tonne by 2050 within our framework. The corresponding emission price reductions induced by the availability of nuclear power and CCS technology are 12 Euro per tonne in the PRIMES model, while POLES reports a corresponding impact on emission prices of 3400 Euro per tonne. These values have to be interpreted on the background of much higher nuclear power plant investments in POLES and PRIMES as reported in the following subsection. 


\subsection{Market driven capacity evolution}

The different scenarios correspond generally to different power plant investment pathways in regard to the conventional technologies fuelled by uranium, coal, and gas. The investment in new conventional power plants in the EU27 is laid out in terms of net generation capacity in Figure 4.

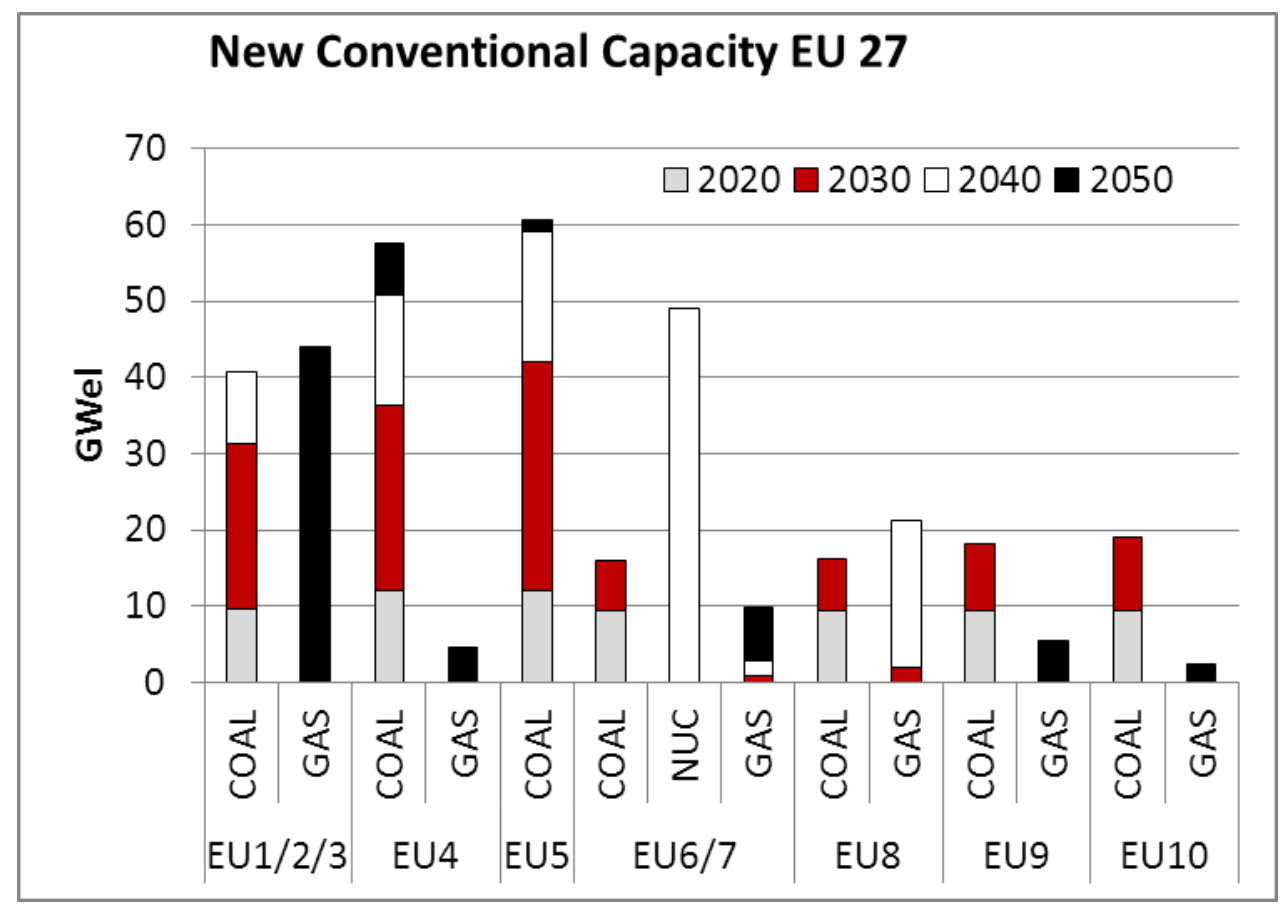

Figure 4: Conventional Capacity Investments until 2050 [GWel net Capacity] (Source: Own illustration)

We find identical outcomes within scenarios EU1/2/3, and within scenarios EU6/7. Since CCS technology is not projected in any scenario, identical outcomes are computed in scenarios EU1 and EU2, and scenarios EU6 and EU7. Furthermore, there are no investments in nuclear energy in scenario EU1, leaving the full set of competitive technologies also in scenario EU3. It is therefore not necessary to separately consider scenarios EU2, EU3 and EU7 in the following, as they can be represented by Scenarios EU1, and EU6. Furthermore, one can distinguish the scenarios by overall conventional capacity investment levels until 2050 into two groups. One group comprises of scenarios EU1 to EU6 where between 60 and $85 \mathrm{GW}$ of new conventional capacities are constructed. In the second group of remaining scenarios EU8 to EU10 only 21 to 37 GW of conventional technologies are incentivized by the markets. Nuclear power plants are newly constructed only in the ambitious policy scenario with low energy efficiency and less ambitious renewable energy roll out EU6/7. Comparing the corresponding scenarios, we find that out of $49 \mathrm{GW}$ of nuclear power plant investment in EU6 only a minor part is compensated by additional $11 \mathrm{GW}$ gas power plant installations in scenario EU8. However, coal fired power plant projects are not impacted by the availability of nuclear power technology. Consequently, total new built capacity reduces by fifty percent from $75 \mathrm{GW}$ in scenario EU6 to about $38 \mathrm{GW}$ in scenario EU8.

Moreover, we find in scenarios of high energy efficiency similar capacity developments, i.e. within pair EU4/EU5 and pair EU9/EU10. Differences within these pairs are only due to the extent of power generation from renewables and to the availability of nuclear power. Since 
the latter plays no role in the non-ambitious emission policy scenario, differences between scenario EU4 and EU5 indicate the effect of a pronounced renewable energy roll out and lead to only minor difference in the timing and technology choice between gas and coal. In scenario EU5 slightly more coal fired power plants are constructed in the last model period 2050, displacing some investment in gas fired power plants. Also only minor differences are obtained for scenarios EU9 and EU10. In EU9 we find slightly more investment in gas fired power plants of $5.4 \mathrm{GW}$ compared to $2.4 \mathrm{GW}$ in EU10. They are partially compensated by about 0.8 GW higher coal power plant investment in period 2030. This shift from gas to coal can be attributed to the lower carbon prices in EU10.

In total, future installed capacity in PRIMES and POLES are significantly higher than in EMELIE-ESY although renewables input is relatively similar across both models. Most notably, PRIMES and POLES set themselves apart from EMELIE-ESY in that they are comparatively optimistic on the deployment of CCS technology for both, gas and coal power plants. PRIMES projects for both scenarios EU1 and EU6 around 50 to $60 \mathrm{GW}$ of CCSequipped coal-fired power plants for the EU by 2050. Moreover, in regard to Gas CCS power plants, PRIMES calculates with investment of around $142 \mathrm{GW}$ in the stringent climate policy scenario EU6, and $41 \mathrm{GW}$ in the EU1 scenario by 2050 respectively. Differences in emission prices of the EU ETS calculated by the models as well as the development of electricity consumption laid out in the following subsections can partly explain these differences.

Similarly, installed nuclear power plant capacity by the year 2050 differs significantly across the compared models. While EMELIE-ESY calculates an installed capacity of $21 \mathrm{GW}$ in scenario EU1, and $72 \mathrm{GW}$ under stringent climate policy, the respective values range between 102 and 156 GW in PRIMES and POLES. Two drivers of these differences can be identified. First and foremost, the investment costs of nuclear capacity is up to 50 percent ${ }^{5}$ lower in POLES, and up to 25 percent lower in PRIMES. Given realized costs of construction and costs of decommissioning in Europe in the last decade, EMELIE-ESY uses a value of 6000 Euro per kilowatt installed net generation capacity in the year 2020. Secondly, the demand development in EMELIE-ESY is dampened by high prices, while other models, e.g. PRIMES and POLES, project an escalating consumption of electricity as documented below.

Notably, we find very low new built conventional capacity investments in our model in the scenarios of ambitious climate policy without the option of nuclear energy (EU8/9/10). We have to stress at this point that our model does not per se provide sufficient capacities to meet system reliability or adequacy, but an energy only market solution. However, system requirements are likely to be fulfilled by cheap single cycle gas turbines or stronger network integration in Europe. Both options would presumably not lead to a significantly distinct picture in power plant generation apart from extreme situations.

5 The relative differences between assumed investment costs for nuclear power plants decrease slightly towards the end of the time horizon. 


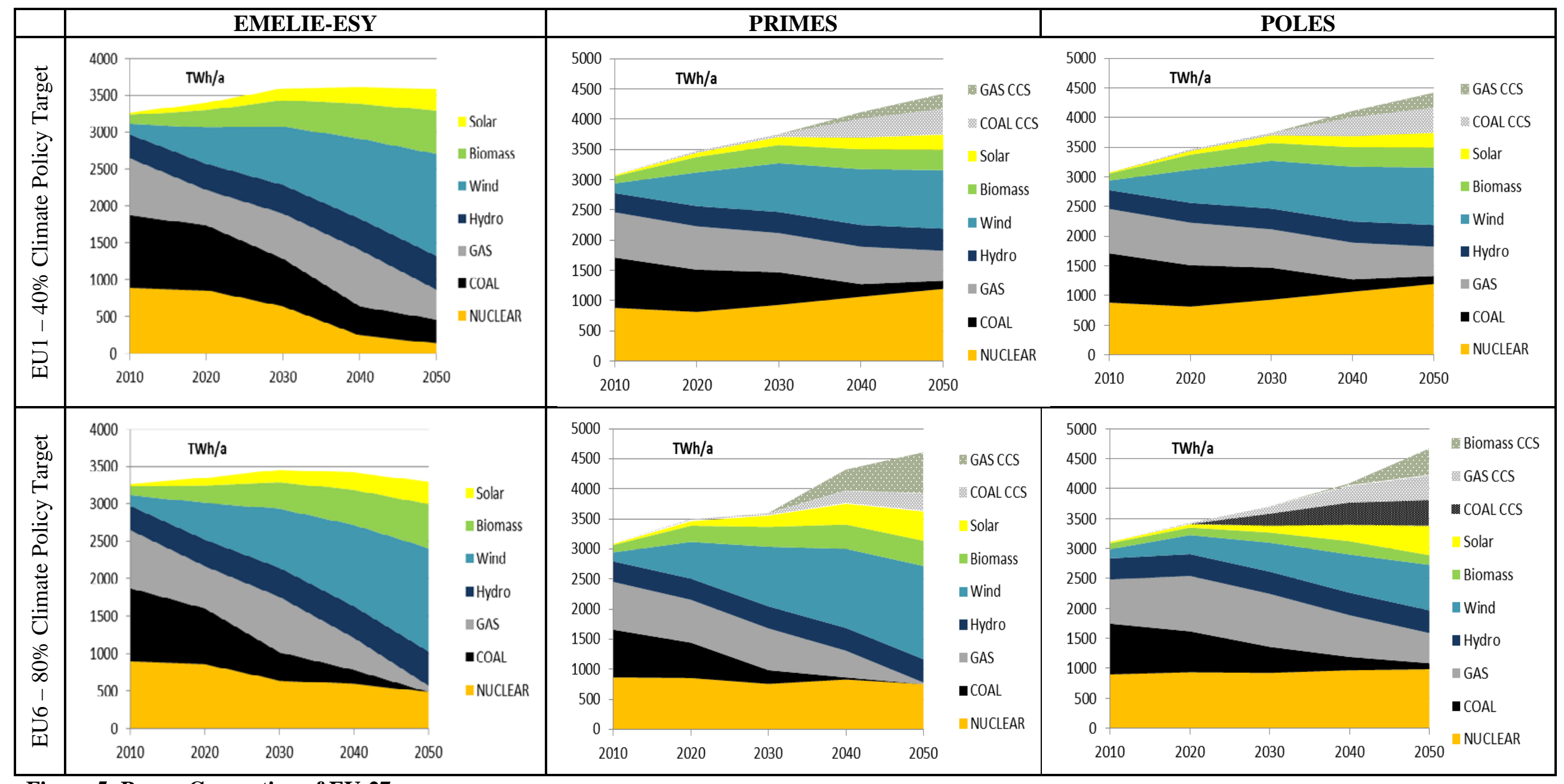

Figure 5: Power Generation of EU-27

(Source: Own compilation) 


\subsection{Power consumption and generation mix}

An important determinant of the market developments and a major explanation for the observed deviations in the results of our model comparison is the development of electricity consumption across the models. The evolution of net power generation, i.e. final consumption including network losses, in the reference case of the two climate policy scenarios EU1 and EU6 are shown in Figure 5. Clearly, the price increases in EMELIE-ESY introduced in subsection 4.1 induce only modest increases or even a stagnant development in consumption, although the reference demand grows significantly over the time horizon. Taking into account price and demand effects, we find a ten percent increase until 2050 in scenario EU1, and little development in scenario EU6, which comprises of an increase until 2030 and a modest decrease afterwards. Quite differently, the two models used for comparison report consumption growth of between 44 and 48 percent compared to the base year 2010, largely unaffected by the stringency of climate policy and the corresponding high emission prices of between 240 and $270 €$ per tonne of carbon dioxide in scenario EU6.

Figure 5 entails also details on power generation by source type. For the less ambitious policy scenario EU1, a fading significance of nuclear power generation in the EU is found in the EMELIE-ESY framework. Starting with a share in power generation of 27 percent in 2010, nuclear energy reaches 24 percent in 2020 and goes down to a four percent share by 2050 . The most important electricity source by 2050 is wind power, followed by biomass and hydro power. Gas power production reduces over time but replaces coal in its position as dominant fossil fuel. While the 2010 reference power mix is similar in PRIMES and EMELIE-ESY, there is a significantly different evolution until 2050. The PRIMES model projects a much larger generation of conventional power plants in general. By 2050, PRIMES projects for the EU 1 scenario all conventional power sources to exceed 50 percent of the EU's power production, with nuclear power as dominant source (27 percent). The share of renewable energy production of around 45 percent in 2050 in PRIMES, contrasts with around 76 percent in EMELIE-ESY. This difference is mainly due to the 27 percent higher power consumption in PRIMES (4545 TWh/year) compared to EMELIE-ESY (3592 TWh/year).

Under the more ambitious climate policy targets of scenario EU6 highlighted in Figure 8, the role of renewable energies gains dominant importance with a production share of 83 percent by 2050. The increase of renewable energy corresponds with a reduction of nuclear power to a share of 15 percent, and an almost complete cutback of fossil fuel usage. Natural gas fired power production keeps an only 2 percent share in power generation, while coal fired power production declines completely. The absence of coal power production arises despite significant coal fired production capacities have not reached their full lifetime by 2050 . Accordingly, gas fuelled powered plants reach only a low rate of utilization, and coal fired power plants are not able to recover fuel and emission costs through electricity prices in the last period. Reduced competitive utilization rates and increasing emission and fuel prices is also a major obstacle for CCS technology investments as modeled in EMELIE-ESY. Since emission rates of CCS are not irrelevant under CO2 prices of over 100 Euro per tonne and the high capital costs of CCS gain importance under low utilization rates, levelized costs of CCS are escalating. We find that under a moderate price elasticity of -0.3 rather demand is displaced than new CCS built.

These findings contrast with the picture drawn by the models PRIMES and POLES, where even in a world of ambitious climate policy fossil fuels keep a significant share in power generation. POLES model calculates a 36 percent share of fossil fuelled power plants in power generation by 2050 in EU6, while Primes projects a corresponding 27 percent share. 
Finally, PRIMES projects a share of nuclear energy of 20 percent, and POLES finds a quarter of European electricity generation produced by nuclear power in the year 2050 for scenario EU6. Given increasing electricity generation, PRIMES therefore finds a ten percent decrease of nuclear power generation compared to today's production, while the model POLES computes an increase of about ten percent with a generation of 985 TWh in 2050.

\section{Conclusion}

We assess potential impacts on electricity prices, CO2 prices and generation capacity investment within the EMF 28 framework under different climate policy regimes. In contrast to other studies as POLES and PRIMES, we do not find such strong investments in CCS and nuclear power. The reason for this is twofold. On the one hand, electricity consumption react more effectively on prices, which rise due to projected fossil fuel prices increase, CO2 price rise and reduced fulload hours due to increased share of renewable energy. On the other hand, we assume high costs for nuclear and CCS installations. Even under current policy no new nuclear plants are competitive and a decline of nuclear power to a minor share of 4 percent is projected for the year 2050. Also in the ambitious climate policy scenario we find a significant drop of nuclear power from currently 850 TWH to 490 TWh or 14 percent in 2050, although the market conditions incentivize towards the mid of the century $49 \mathrm{GW}$ of new nuclear power plants.

A major difference of our model results compared to other models is obtained in regard to electricity consumption, which increases only slightly or even reduces due to pronounced wholesale electricity price increases and assumed demand elasticity. These findings contrasts with reference results of the models PRIMES and POLES which reports a comparatively stable increase of electricity consumption by 2050, despite high emission prices. We find that renewable energy supply extension as projected can sufficiently meet electricity consumption complemented by only few capacity investments in conventional technology.

\section{References}

EC, 2011. Energy Roadmap 2050, Brussels: European Commission.

EEA (2012). Annual European Union greenhouse gas inventory 1990-2010 and inventory report 2012. http://www.eea.europa.eu/publications/european-union-greenhouse-gas-inventory-2012.

ENTSO-E, 2012. NTC Values - Intro to the NTC Matrix and BCE Maps, Brussels: European Network of Transmission System Operators for Electricity. Available at:

https://www.entsoe.eu/resources/ntc-values/ [Accessed October 15, 2012].

IEA, 2011. World Energy Model - Methodology and Assumptions, Paris: International Energy Agency. Available at: http://www.iea.org/weo/docs/weo2011/other/WEO_methodology/WEM_Methodology_WEO 2011.pdf [Accessed April 15, 2012].

Platts, 2011. World Electric Power Plants Database: Global Price Assessments and Indices. Available at: http://www.platts.com/Products/worldelectricpowerplantsdatabase [Accessed January 25, 2011]. 
Schroeder, A., Kunz, F., Mendelevitch, R. \& Hirschhausen, C., forthcoming. Current and Prospective Costs for Electricity Generation, Berlin: DIW Berlin.

Traber, T. \& Kemfert, C., 2012. German Nuclear Phase-out Policy - Effects on European Electricity Wholesale Prices, Emission Prices, Conventional Power Plant Investments and Electricity Trade, DIW- Discussionpaper 1219, downloadable at www.diw.de

Traber, T. \& Kemfert, C., 2011a. Gone with the Wind?-Electricity Market Prices and Incentives to Invest in Thermal Power Plants under Increasing Wind Energy Supply. Energy Economics, 33(2), pp.249-256.

Traber, T. \& Kemfert, C., 2011b. Refunding ETS Proceeds to Spur the Diffusion of Renewable Energies: An Analysis Based on the Dynamic Oligopolistic Electricity Market Model EMELIE. Utilities Policy, 19(1), pp.33-41. 